\title{
Susceptibility to Atherosclerosis in Mice Expressing Exclusively Apolipoprotein B48 or Apolipoprotein B100
}

\author{
Murielle M. Véniant, ${ }^{\star \ddagger}$ Vincenzo Pierotti, ${ }^{*}$ Dale Newland, ${ }^{*}$ Candace M. Cham, ${ }^{*}$ David A. Sanan, ${ }^{\star \ddagger}$ Rosemary L. Walzem, \\ and Stephen G. Young ${ }^{\star \neq \S}$ \\ * Gladstone Institute of Cardiovascular Disease, San Francisco, California 94141-9100; ${ }^{\ddagger}$ Cardiovascular Research Institute, and \\ ${ }^{\S}$ Department of Medicine, University of California, San Francisco, California 94143; and ${ }^{\|}$Department of Molecular Biosciences, School of \\ Veterinary Medicine, University of California, Davis, California 95616
}

\section{Abstract}

All classes of lipoproteins considered to be atherogenic contain apo-B100 or apo-B48. However, there is a distinct paucity of data regarding whether lipoproteins containing apoB48 or apo-B100 differ in their intrinsic ability to promote the development of atherosclerosis. To address this issue, we compared the extent of atherosclerosis in three groups of animals: apo-E-deficient mice (apo- $B^{+/+}$apo- $E^{-/-}$) and apoE-deficient mice that synthesize exclusively either apo-B48 $\left(\right.$ apo- $B^{48 / 48}$ apo- $\left.E^{-1-}\right)$ or apo-B100 (apo-B ${ }^{100 / 100}$ apo- $\left.E^{-l-}\right)$. Mice ( $n=25$ in each group) were fed a chow diet for 200 days, and plasma lipid levels were assessed throughout the study. Compared with the levels in apo- $B^{+/+}$apo- $E^{-/-}$mice, the total plasma cholesterol levels were higher in the apo$B^{48 / 48}$ apo- $E^{-1-}$ mice and were lower in the apo- $B^{100 / 100}$ apo$E^{-l-}$ mice. However, the ranges of cholesterol levels in the three groups overlapped. Compared with those in the apo- $B^{+/+}$apo- $E^{-1-}$ mice, atherosclerotic lesions were more extensive in the apo- $B^{48 / 48}$ apo- $E^{-l-}$ mice and less extensive in the apo- $B^{100 / 100}$ apo- $E^{-l-}$ mice. Once again, however, there was overlap among the three groups. The extent of atherosclerosis in each group of mice correlated significantly with plasma cholesterol levels. In mice from different groups that had similar cholesterol levels, the extent of atherosclerosis was quite similar. Thus, susceptibility to atherosclerosis was dependent on total cholesterol levels. Whether mice synthesized apo-B48 or apo-B100 did not appear to have an independent effect on susceptibility to atherosclerosis. (J. Clin. Invest. 1997. 100:180-188.) Key words: triglycerides • lipoproteins • apo-E deficiency • morphometric lesion analysis • body weight

\section{Introduction}

The B apolipoproteins (apo-B100 and apo-B48) have been studied extensively because they play central roles in lipoprotein assembly and plasma lipid metabolism $(1,2)$. Apo-B100 (4,536 amino acids) is essential for the assembly of VLDL in

Address correspondence to Murielle M. Véniant, Gladstone Institute of Cardiovascular Disease, P.O. Box 4191000, San Francisco, CA 94141-9100. Phone: 415-826-7500; FAX: 415-285-5632; E-mail: murielle_veniantGICD@quickmail.ucsf.edu

Received for publication 6 February 1997 and accepted in revised form 4 April 1997.

J. Clin. Invest.

(C) The American Society for Clinical Investigation, Inc.

0021-9738/97/07/0180/09 \$2.00

Volume 100, Number 1, July 1997, 180-188 the liver, while apo-B48 (which contains the amino-terminal 2,152 amino acids of apo-B100) is required for chylomicron formation in the intestine. In addition to their lipid-transport roles, these two proteins have attracted interest because all of the classes of apo-B-containing lipoproteins LDL, intermediary density lipoproteins (IDL), ${ }^{1}$ chylomicron and VLDL remnants, and lipoprotein(a) are thought to play a causal role in the development of atherosclerosis $(1,2)$. The atherogenicity of apo-B-containing lipoproteins has not been explained fully, but it is generally believed that the physical properties of apoB-containing lipoproteins cause them to be retained within the arterial wall (3), where they undergo chemical and physical modifications that confer a number of different pro-atherogenic properties (4). For example, the avid uptake of modified LDL by macrophages likely contributes to foam cell formation (5). In addition, the modified LDL almost certainly lead to the recruitment of monocytes into the arterial wall $(6,7)$.

Over the past few years, we have been interested in whether apo-B48- and apo-B100-containing lipoproteins have intrinsically different abilities to promote atherosclerosis. Profound differences in their atherogenicity are easy to imagine because the structures of the two proteins differ substantially. For example, apo-B100 contains nearly 2,400 more amino acid residues than apo-B48, including several strong heparin-binding regions (8). These unique structural features might make apo-B100-containing lipoproteins bind much more avidly to the arterial wall matrix than apo-B48-containing lipoproteins. If so, apo-B100-containing lipoproteins might be substantially more atherosclerogenic than apo-B48-containing lipoproteins, even when the plasma lipid levels are comparable. It is also possible that all of the sequences relevant to atherogenesis reside in the amino-terminal portion of the apo-B moleculedomain shared by apo-B48 and apo-B100 - in which case the apo-B48- and apo-B100-containing lipoproteins might be equally atherogenic.

In humans, there are few data by which to judge the relative atherogenicities of apo-B48- and apo-B100-containing lipoproteins. One school of thought holds that the postprandial remnant lipoproteins might be particularly atherogenic $(9,10)$, but these lipoproteins contain both apo-B48 and apo-B100, making it difficult to implicate apo-B48-containing lipoproteins as the culprit (11). In recent years, human apo-B transgenic mice $(12,13)$, apo-E-deficient mice $(14,15)$, and LDL receptor-deficient mice (16) have been used to study atherosclerosis. However, these mice have not provided definitive insights into the atherogenicities of apo-B48 and apo-B100; because all of these mice synthesize both apo-B48 and apo-B100,

1. Abbreviations used in this paper: FPLC, fast performance liquid chromatography; IDL, intermediary density lipoproteins. 
it is difficult to infer that one form of apo-B is more atherogenic than the other. On a chow diet, human apo-B transgenic mice do not develop atherosclerosis when apo-B100 predominates in the plasma. On a high-fat diet, however, they develop severe atherosclerosis in the setting of total cholesterol levels of $\sim 300 \mathrm{mg} / \mathrm{dl}$ and a huge increase in apo-B48-containing lipoproteins (17). Apo-E-deficient mice, which have a disproportionate amount of apo-B48-containing lipoproteins, attain total cholesterol levels of $\sim 450 \mathrm{mg} / \mathrm{dl}$ on a chow diet and develop severe atherosclerotic lesions $(14,15)$. LDL receptordeficient mice, which have a disproportionate increase in apoB100, have total cholesterol levels of $\sim 250 \mathrm{mg} / \mathrm{dl}$ on a chow diet and develop only negligible atherosclerotic lesions (16). On a high-fat diet, however, the LDL receptor-deficient mice develop severe atherosclerosis (16). These observations, taken together, might lead one to suspect that both forms of apo-B could be atherogenic. However, they do not permit even tentative conclusions regarding intrinsic differences in the capacities of apo-48- and apo-B100-containing lipoproteins to promote atherosclerosis.

Gaining insights into the relative atherogenicities of apoB48 and apo-B100 represents a fundamental step in understanding why the apo-B-containing lipoproteins cause atherosclerosis. To address the issue of the atherogenicities of apo-B48 and apo-B100, we used gene targeting in embryonic stem cells to create mice that synthesized either exclusively apo-B48 (apo-B48-only mice) or exclusively apo-B100 (apo-B100-only mice) (18). In this study, we compared the extent of atherosclerosis in apo-B48-only and apo-B100-only mice in the setting of apo-E deficiency.

\section{Methods}

Generation of apo-E-deficient mice that synthesize exclusively apo$B 48$ or apo-B100. Mice that synthesize exclusively apo-B48 (apoB48-only mice or apo- $B^{48 / 48}$ mice) or exclusively apo-B100 (apo-B100only mice or apo- $B^{100 / 100}$ mice) (18) were bred with apo-E-deficient mice $\left(\right.$ apo- $\left.E^{-/-}\right)(19)$ to generate apo- $B^{48 / 48}$ apo- $E^{-/-}$and apo- $B^{100 / 100}$ apo- $E^{-1-}$ mice. Genotyping was performed by Southern blot and PCR analysis of tail DNA. In the course of breeding these mice, we generated a third group of animals that were used as controls: apo-Edeficient mice that were homozygous for the wild-type apo-B allele (apo- $B^{+/+}$apo- $E^{-/-}$). All three groups had similar genetic backgrounds ( $\sim 75 \%$ C57BL/6 and 25\% 129/Sv). All mice were weaned at $21 \mathrm{~d}$ and fed a chow diet containing $4.5 \%$ fat (Ralston Purina Co., St. Louis, MO). Only female mice were used in our studies; they were housed (3-5 mice per cage) in a full-barrier transgenic facility. Each mouse was weighed at $7 \mathrm{wk}$, and 3 and 6 mo of age. All mice were killed at exactly $200 \mathrm{~d}$ of age.

Western blotting and analysis of apolipoprotein distribution. To assess the apo-B48 and apo-B100 content of mouse plasma, $2 \mu \mathrm{l}$ of plasma was size-fractionated on a $4 \%$ polyacrylamide-SDS gel; the separated proteins were then transferred to a sheet of nitrocellulose membrane for Western blot analysis with a rabbit antiserum specific for mouse apo-B (20) and a ${ }^{125}$ I-labeled goat anti-rabbit secondary antibody. To assess the distribution of apo-B48 and apo-B100 among the plasma lipoproteins, pooled plasma from four female mice of each genotype (apo- $B^{48 / 48}$ apo- $E^{-/-}$, apo- $B^{100 / 100}$ apo- $E^{-/-}$, and apo- $B^{+/+}$ apo- $E^{-l-}$ ) was fractionated on a Superose 6B 10/50 column (Pharmacia LKB Biotechnology, Piscataway, NJ) and analyzed by Western blot as described previously $(12,21)$.

Analysis of the plasma lipoproteins sizes. For each group, three different lipoprotein fractions (VLDL $[d<1.006 \mathrm{~g} / \mathrm{ml}]$, IDL $[d=$ $1.006-1.020 \mathrm{~g} / \mathrm{ml}]$, and LDL $[d=1.020-1.063 \mathrm{~g} / \mathrm{ml}])$ were prepared by sequential ultracentrifugation of pooled plasma. Lipoprotein particle diameters were determined optically by dynamic light scattering analysis with a Microtrak Series 9200 Ultrafine Particle Analyzer (Leeds and Northrup, North Wales, PA) as described previously (22). These experiments were performed on three independent preparations of lipoproteins from different apo- $B^{48 / 48}$ apo- $E^{-/-}$apo- $B^{100 / 100}$ apo- $E^{-/-}$and apo- $B^{+/+}$apo- $E^{-/-}$mice. In parallel with these experiments, VLDL sizes were assessed in three groups of apo-E-expressing mice (apo- $B^{48 / 48}$, apo- $B^{100 / 100}$, and apo- $\left.B^{+/+}\right)$. Lipoprotein sizes were also determined by negative-staining electron microscopy as described previously $(23,24)$.

Plasma lipid measurements. Female mice ( $n=25$ in each group) were anesthetized with metophane, and blood was collected from the retroorbital sinus. Total plasma cholesterol and triglyceride concentrations were measured with colorimetric assays on fresh plasma samples (Spectrum cholesterol assay; Abbott Laboratories, Irving, TX, and GB triglyceride kit; Boehringer Mannheim Biochemicals, Indianapolis, IN). Total cholesterol and triglyceride levels were measured at $7 \mathrm{wk}$, and 3 and 6 mo of age; cholesterol levels were also measured when the animals were killed (200 d). Both primary and secondary standards were included in each assay. To confirm their accuracy, all cholesterol determinations were repeated at the end of the study, using plasma samples that had been stored at $-70^{\circ} \mathrm{C}$. HDL cholesterol levels were determined at $200 \mathrm{~d}$ of age after the precipitation of the apo-B-containing lipoproteins with polyethylene glycol-8000 as described previously $(12,25)$.

Analysis of atherosclerotic lesions. All animals were entered into the study at exactly $21 \mathrm{~d}$ of age and killed at exactly $200 \mathrm{~d}$ of age. Atherosclerosis was assessed by two independent techniques: by quantifying sudanophilic lesions in pinned-out aortas and by quantifying Oil Red O-staining lesions in cross sections from the aortic root. To quantify atherosclerosis along the entire aorta, the aortic tree was dissected out and analyzed, essentially as described by Tangirala et al. (26). Briefly, female mice ( $n=25$ in each group) were perfused with PBS for 3 min through a cannula inserted into the left ventricle. The tissues were then fixed by perfusing the mouse for 20 min with a fixative solution (4\% paraformaldehyde, $5 \%$ sucrose, 20 mmol EDTA, $\mathrm{pH}$ 7.4). With the major branching vessels still attached, the aorta was opened longitudinally from the iliac arteries to the aortic root. Then, all branching vessels were removed, including the great vessels in the neck, and a segment of the aorta (from the iliac bifurcation to a point equidistant between the aortic valve and the bracheocephalic artery) was removed and pinned out flat on a black wax surface, care being taken not to place pins through atherosclerotic lesions. The lesions were stained with Sudan IV for 6 min, destained with $80 \%$ ethanol for $3 \mathrm{~min}$, and then washed and stored in the fixative solution. Sudanophilic lesions were assessed by computer-assisted image analysis (see below).

For microscopic analysis of atherosclerotic lesions in the proximal aortic root, the heart and $1 \mathrm{~mm}$ of the thoracic aorta were removed, embedded in Tissue-Tek OCT cryostat molds (Miles Laboratories, Inc., Elkhart, IN), and frozen at $-20^{\circ} \mathrm{C}$. These tissues were used to generate $10-\mu \mathrm{m}$-thick cross sections of the proximal aorta. Using a cryostat, 60 sections of the aortic root were obtained at $20-\mu \mathrm{m}$ intervals, beginning at the level of the attachment of the aortic valve cusps to the aortic ring. Tissue sections were stained in $0.5 \%$ Oil Red O in propylene glycol for $4 \mathrm{~h}$ and counterstained with Mayer's hematoxylin for $1 \mathrm{~min}$. For 17 randomly selected animals of each group of 25 mice, the lesions in five aortic cross sections (at $80-\mu \mathrm{m}$ intervals) were quantified by computer-assisted morphometric analysis, with the most proximal section located at the take-off of the first coronary artery from the aorta (typically about the 20th section of the 60 progressive sections).

Image analysis. Image analysis of the pinned-out aortas was performed by a trained observer without knowledge of the genotype of the mice. Images of the pinned-out aortas and the microscopic sections were viewed with a color video camera (CCD-IRIS; Sony, Tokyo, Japan) mounted with an Optem $2 / 3$ photo-eyepiece adapter to one ocular of a light microscope (Standard RA; Carl Zeiss, Inc., 
Thornwood, NY). Each image was captured into the framestores of an Image-1/AT image-analysis system (software version 4.03a; Universal Imaging Corp., West Chester, PA). To assess the extent of lesions in the pinned-out aortas, the amount of Sudan-IV staining was measured, using color thresholding to delimit areas of staining. Data are reported as the percentage of the aortic surface covered by lesions (total surface area of the atherosclerotic lesions, in $\mu \mathrm{m}^{2}$, divided by the total surface area of the aorta). Lesions were also quantified in the aortic arch, the thoracic aorta, and the abdominal aorta.

For the analysis of aortic cross sections, the lesions in five sections at $80-\mu \mathrm{m}$ intervals were quantified exactly as described previously (17), again using color thresholding to delimit areas of Oil Red O staining. The amount of atherosclerosis was recorded as the mean lesion area per section.

Statistical analysis. Mean lipid levels are reported with the SEM. Differences in triglyceride levels, cholesterol levels, and weights were modeled by repeated-measures ANOVA with time being an intragroup factor and genotype an intergroup factor. Statistical significance was calculated for both factors. The extent of atherosclerotic lesions in the pinned-out aortas is reported as the mean and SEM for each group of mice. Differences in the extent of atherosclerosis in the pinned-out aortas were assessed by ANOVA. Because aortic crosssectional data were not normally distributed, the median extent of atherosclerosis $\left(\right.$ in $\mu \mathrm{m}^{2}$ ) is reported, along with the range for each group, and differences in the extent of atherosclerosis between groups were analyzed with the nonparametric Kruskal-Wallis test. The association of lesions in the cross sections of the proximal aorta with lesions in the pinned-out aortas was measured by rank correlations. Relationships between lipid levels, body weights, and the extent of atherosclerotic lesions were assessed by both univariate and multivariate analysis to determine if genotype had an independent impact on lesion area. Analyses were performed on a Sun SparcStation 2 (Sun Microsystems, Inc., Fremont, CA) using the statistical analysis system procedures (SAS Institute, Inc., Cary, NC) MIXED, GLM, UNIVARIATE, NPAR1WAY and CORR

\section{Results}

Characterization of the genetically modified mice. Although the plasma of the apo- $B^{+/+}$apo- $E^{-/-}$mice contained both apo-B48 and apo-B100, 80-90\% of the apo-B was apo-B48 (Fig. $1 A$ ). The plasma of the apo- $B^{48 / 48}$ apo- $E^{-/-}$contained exclusively apo-B48, whereas the plasma of the apo- $B^{100 / 100}$ apo- $E^{-/-}$mice produced only apo-B100. Quantitative analysis of Western blots with a PhosphorImager revealed that the apo-B48 levels in the apo- $B^{48 / 48}$ apo- $E^{-1-}$ mice were slightly more than those of the apo- $B^{+/+}$apo- $E^{-/-}$mice, and the apo-B100 levels in the apo- $B^{100 / 100}$ apo- $E^{-1-}$ mice were approximately threefold more than in the apo- $B^{+/+}$apo- $E^{-/-}$mice. As judged by fast performance liquid chromatography (FPLC) fractionation studies, there were no major differences in overall distribution of the two apolipoproteins in the different lipoprotein fractions. Apo-B48 was broadly distributed across the VLDL, IDL, and LDL fractions in the apo- $B^{48 / 48}$ apo- $E^{-/-}$mice, and apo-B100 was broadly distributed in essentially the same fractions in the apo- $B^{100 / 100}$ apo- $E^{-/-}$mice (Fig. $1 B$ ).

Lipid levels. The total cholesterol levels in the apo- $B^{48 / 48}$ apo- $E^{-/-}$mice were higher than in the apo- $B^{+/+}$apo- $E^{-/-}$mice at $7 \mathrm{wk}$, and 3 and $6 \mathrm{mo}$, and $200 \mathrm{~d}$, although the difference reached statistical significance only at $200 \mathrm{~d}(P=0.035)$. At 7 $\mathrm{wk}$, the total cholesterol levels in the apo- $B^{100 / 100}$ apo- $E^{-1-}$ mice $(247 \pm 21 \mathrm{mg} / \mathrm{dl})$ were significantly lower $(P<0.001)$ than in the apo- $B^{48 / 48}$ apo- $E^{-/-}$mice $(392 \pm 21 \mathrm{mg} / \mathrm{dl})$ or the apo- $B^{+/+}$ apo- $E^{-1-}$ mice $(341 \pm 23 \mathrm{mg} / \mathrm{dl})$; these differences remained highly significant at 3 and $6 \mathrm{mo}$, and $200 \mathrm{~d}$ (Fig. 2). In repeated
A

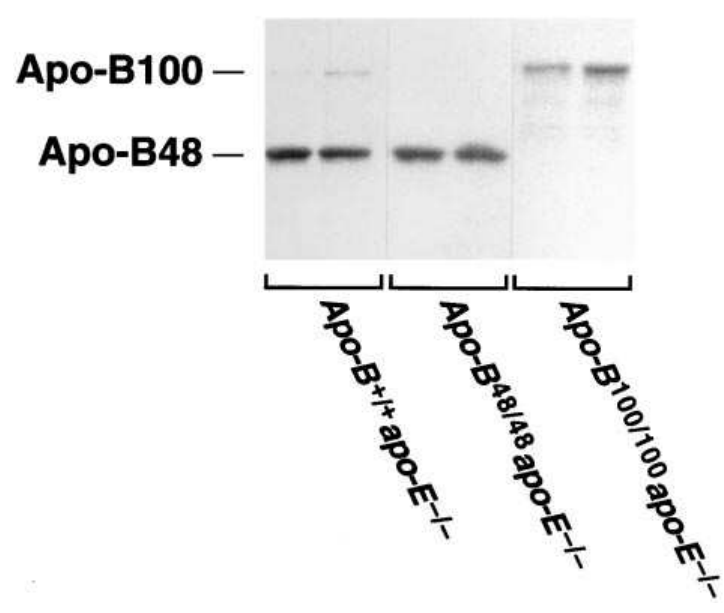

B

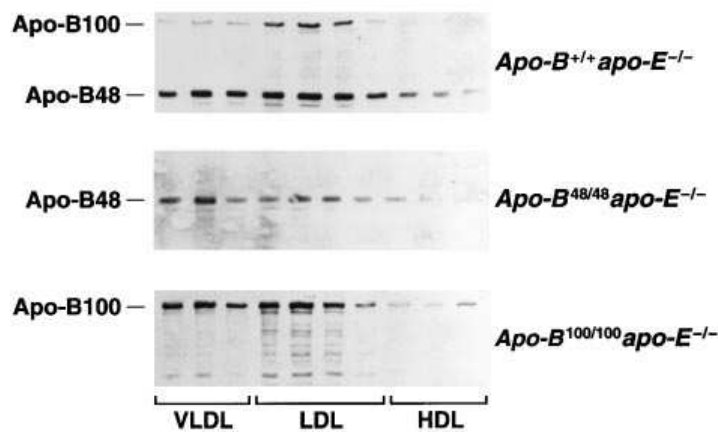

Figure 1. (A) Western blot illustrating apo-B proteins in the plasma of apo- $B^{+/+}$apo- $E^{-/-}$apo- $B^{48 / 48}$ apo- $E^{-/-}$, and apo- $B^{100 / 100}$ apo- $E^{-/-}$ mice. $(B)$ Plasma was pooled from four mice of each genotype and size-fractionated on a Superose 6 column. Consecutive fractions were combined and electrophoresed on 4-15\% polyacrylamide-SDS gels. Western blots were performed with a rabbit antiserum to mouse apo-B (20), and with a ${ }^{125}$ I-labeled goat anti-rabbit secondary antibody.

FPLC fractionation studies, all three groups had very high levels of VLDL cholesterol, and the differences in total cholesterol levels were accounted for by different amounts of cholesterol in IDL- and LDL-sized lipoproteins (18). HDL cholesterol levels at $200 \mathrm{~d}$ were slightly, but significantly, higher $(P<0.001)$ in the apo- $B^{100 / 100}$ apo- $E^{-l-}$ mice $(33.8 \pm 1.36 \mathrm{mg} / \mathrm{dl})$, than in the apo- $B^{+/+}$apo- $E^{-/-}$mice $(22.1 \pm 1.5 \mathrm{mg} / \mathrm{dl})$ and the apo- $B^{48 / 48}$ apo- $E^{-1-}$ mice $(27.7 \pm 1.5 \mathrm{mg} / \mathrm{dl})$. The triglyceride levels were significantly higher in the apo- $B^{100 / 100}$ apo- $E^{-/-}$mice than in the apo- $B^{+/+}$apo- $E^{-/-}$control mice, but there were no differences in triglyceride levels between the apo- $B^{48 / 48}$ apo- $E^{-/-}$and apo- $B^{+/+}$apo- $E^{-/-}$mice (Table I).

The plasma cholesterol levels increased significantly with time in both the apo- $B^{48 / 48}$ apo- $E^{-/-}$mice $(P=0.0002)$ and the apo- $B^{+/+}$apo- $E^{-/-}$mice $(P=0.0065)$. In striking contrast, the plasma cholesterol levels decreased in the apo- $B^{100 / 100}$ apo- $E^{-/-}$ mice $(P=0.053)$. In the apo- $B^{48 / 48}$ apo- $E^{-/-}$mice and apo- $B^{+/+}$ apo- $E^{-1-}$ mice, cholesterol levels measured at 7 wk correlated weakly with those measured at $200 \mathrm{~d}(r=0.460, P=0.020$ for the apo- $B^{48 / 48}$ apo- $E^{-1-}$ mice; $r=0.207, P=0.321$ for the 


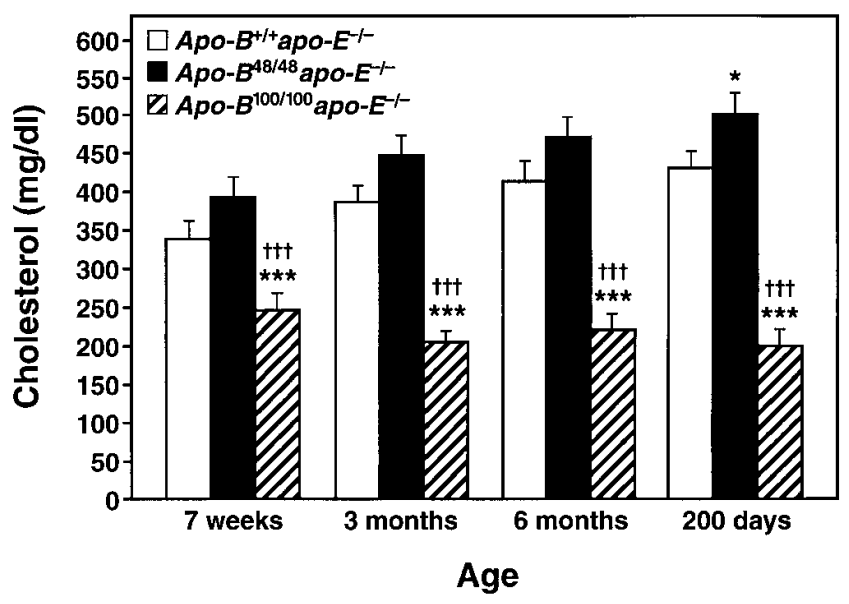

Figure 2. Mean plasma cholesterol levels in apo- $B^{+/+}$apo- $E^{-/-}$, apo- $B^{48 / 48}$ apo- $E^{-/-}$, and apo- $B^{100 / 100}$ apo- $E^{-l-}$ mice fed a chow diet at $7 \mathrm{wk}, 3$ and $6 \mathrm{mo}$, and $200 \mathrm{~d}$ of age. Error bars represent SEM. $* P<$ 0.05 versus apo- $B^{+/+}$apo- $E^{-/-} ; * * * P<0.001$ versus apo- $B^{+/+}$ apo- $E^{-/-} ;{ }^{\dagger \dagger} P<0.001$ versus apo- $B^{48 / 48}$ apo- $E^{-/-}$.

apo- $B^{+/+}$apo- $E^{-/-}$mice). In the apo- $B^{100 / 100}$ mice, the correlation was somewhat stronger $(r=0.574, P=0.0041)$.

Body weights. Unexpectedly, we found that the body weights of the three groups of animals were slightly different (Fig. 3). Compared with the apo- $B^{+/+}$apo- $E^{-1-}$ mice at $200 \mathrm{~d}$ of age, the apo- $B^{100 / 100}$ apo- $E^{-/-}$mice were slightly, but significantly, lighter $(P<0.001)$, whereas the apo- $B^{48 / 48}$ apo- $E^{-1-}$ mice were heavier $(P<0.05)$ (Fig. 3).

Atherosclerosis. Atherosclerosis was quantified by two independent techniques: measurement of sudanophilic lesions in the pinned-out aortas and measurement of Oil Red O-staining lesions cross sections of the aortic root. The analysis of the pinned-out aortas revealed that the apo- $B^{48 / 48}$ apo- $E^{-/-}$mice had significantly more lesions than the apo- $B^{+/+}$apo- $E^{-/-}$mice $(P<0.001)$, whereas the apo- $B^{100 / 100}$ apo- $E^{-/-}$mice had significantly fewer lesions $(P<0.001)$ (Fig. 4). A representative example of an entire aorta from a single apo- $B^{48 / 48}$ apo- $E^{-1-}$ mouse is shown in Fig. $5 \mathrm{~A}$. Most of the lesions were located in the aortic arch, although some lesions extended into the thoracic and abdominal aortas. Representative aortic arch regions from apo- $B^{+/+}$apo- $E^{-/-}$, apo- $B^{48 / 48}$ apo- $E^{-/-}$, and apo- $B^{100 / 100}$ apo- $E^{-l-}$ aortas are shown in Fig. $5 B, C$, and $D$, respectively. In each aortic segment (arch, thoracic, and abdominal), the apo- $B^{100 / 100}$ apo- $E^{-l-}$ mice had less atherosclerosis than the

Table I. Plasma Triglyceride Levels in the Three Groups of Mice

\begin{tabular}{cccc}
\hline & \multicolumn{3}{c}{ Plasma triglyceride levels $(\mathrm{mg} / \mathrm{dl})$} \\
\cline { 2 - 4 } Genotype & $7 \mathrm{wk}$ & $3 \mathrm{mo}$ & $6 \mathrm{mo}$ \\
\hline apo- $B^{+/+}$apo- $E^{-/-}$ & $80.9 \pm 5.7$ & $102.0 \pm 8.5$ & $73.4 \pm 7.2$ \\
apo- $B^{48 / 48}$ apo- $E^{-/-}$ & $96.6 \pm 17.1$ & $88.0 \pm 8.6$ & $76.1 \pm 7.4$ \\
apo- $B^{100 / 100}$ apo- $E^{-/-}$ & $133.1 \pm 9.2^{*}$ & $128.6 \pm 8.4^{*}$ & $109.5 \pm 8.1^{*}$
\end{tabular}

$n=25$ in each group; $* P<0.01$ versus apo- $B^{+/+}$apo- $E^{-/-}$and apo- $B^{48 / 48}$ apo- $E^{-1-}$ mice.

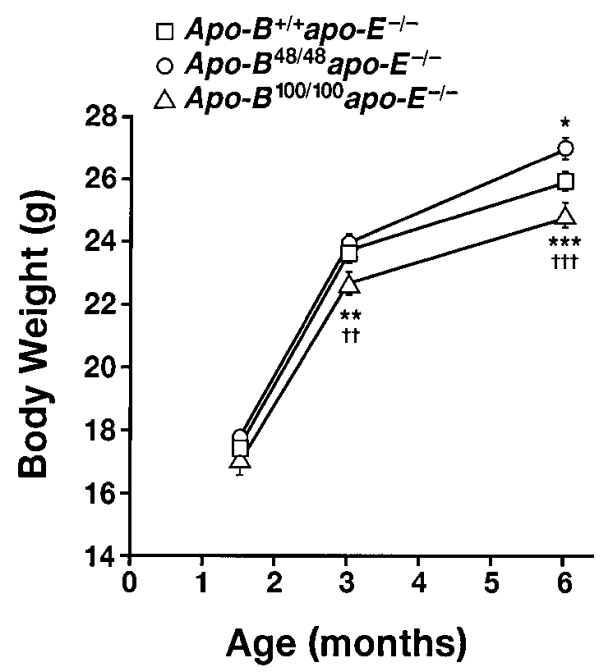

Figure 3. Body weights of apo- $B^{+/+}$apo- $E^{-/-}$, apo- $B^{48 / 48}$ apo- $E^{-/-}$, and apo- $B^{100 / 100}$ apo- $E^{-/-}$mice at $7 \mathrm{wk}$, and 3 and 6 mo of age. Body weights at 6 mo were $26.1 \pm 0.3 \mathrm{~g}$ in apo- $B^{+/+}$apo- $E^{-/-}$mice, $26.9 \pm 0.3 \mathrm{~g}$ in apo- $B^{48 / 48}$ apo- $E^{-/-}$mice, and $24.7 \pm 0.4 \mathrm{~g}$ in apo- $B^{100 / 100}$ apo- $E^{-/-}$ mice. ${ }^{*} P<0.05$ versus apo- $B^{+/+}$apo- $E^{-/-} ; * * P<0.01$ versus apo- $B^{+/+}$ apo- $E^{-/-}$mice; ${ }^{* * *} P<0.001$ versus apo- $B^{+/+}$apo- $E^{-/-}$mice; ${ }^{\dagger \dagger} P<$ 0.01 versus apo- $B^{48 / 48}$ apo- $E^{-/-} ; \dagger^{\dagger \dagger} P<0.001$ versus apo- $B^{48 / 48}$ apo- $E^{-l-}$.

apo- $B^{+/+}$apo- $E^{-/-}$or apo- $B^{48 / 48}$ apo- $E^{-/-}$mice (Fig. 4). The apo- $B^{48 / 48}$ apo- $E^{-1-}$ mice tended to have more atherosclerosis than the apo- $B^{+/+}$apo- $E^{-/-}$mice in each of the three segments, although the difference between these two groups did not reach statistical significance in the aortic arch segment (Fig. 4).

The results illustrated in Figs. 2 and 4 show that the extent of atherosclerotic lesions was greatest in the apo- $B^{48 / 48}$ apo- $E^{-/-}$ mice, which had the highest mean cholesterol level, and lowest

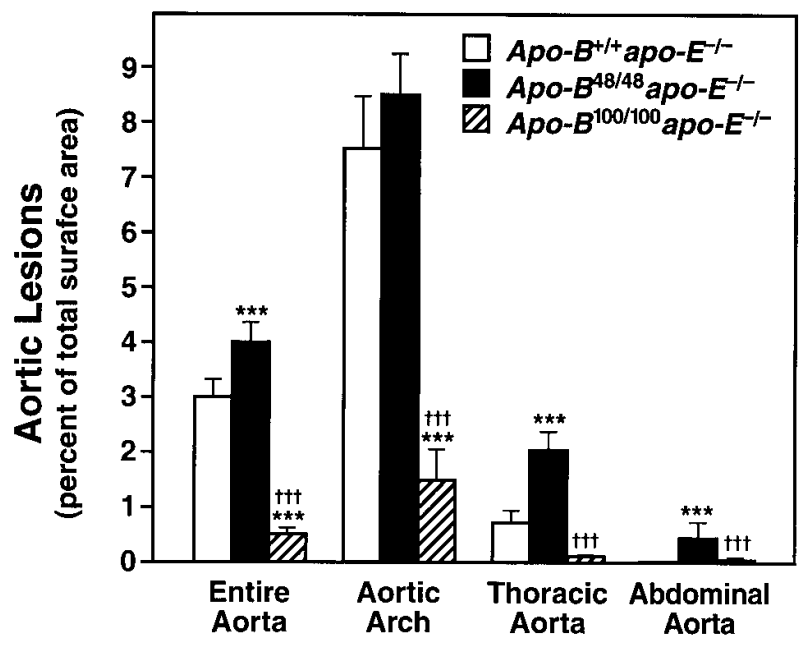

Figure 4. Extent of the atherosclerotic lesions in the entire aorta, the aortic arch, the thoracic aorta, and the abdominal aorta in apo- $B^{+/+}$ apo- $E^{-/-}$, apo- $B^{48 / 48}$ apo- $E^{-/-}$, and apo- $B^{100 / 100}$ apo- $E^{-/-}$mice $(n=25$ in each group). Mean lesion surface area $( \pm$ SEM) for the entire aorta were $268,858 \pm 35,897$ for the apo- $B^{+/+}$apo- $E^{-/-}$mice, $355,653 \pm 34,877$ for the apo- $B^{48 / 48}$ apo- $E^{-1-}$ mice, and $48,537 \pm 13,149 \mu \mathrm{m}^{2}$ for the apo- $B^{100 / 100}$ apo- $E^{-/-}$mice. $* * * P<0.001$ versus apo- $B^{+/+}$apo- $E^{-/-}$ mice; ${ }^{\dagger \dagger} P<0.001$ versus apo- $B^{48 / 48}$ apo- $E^{-/-}$. 
A.
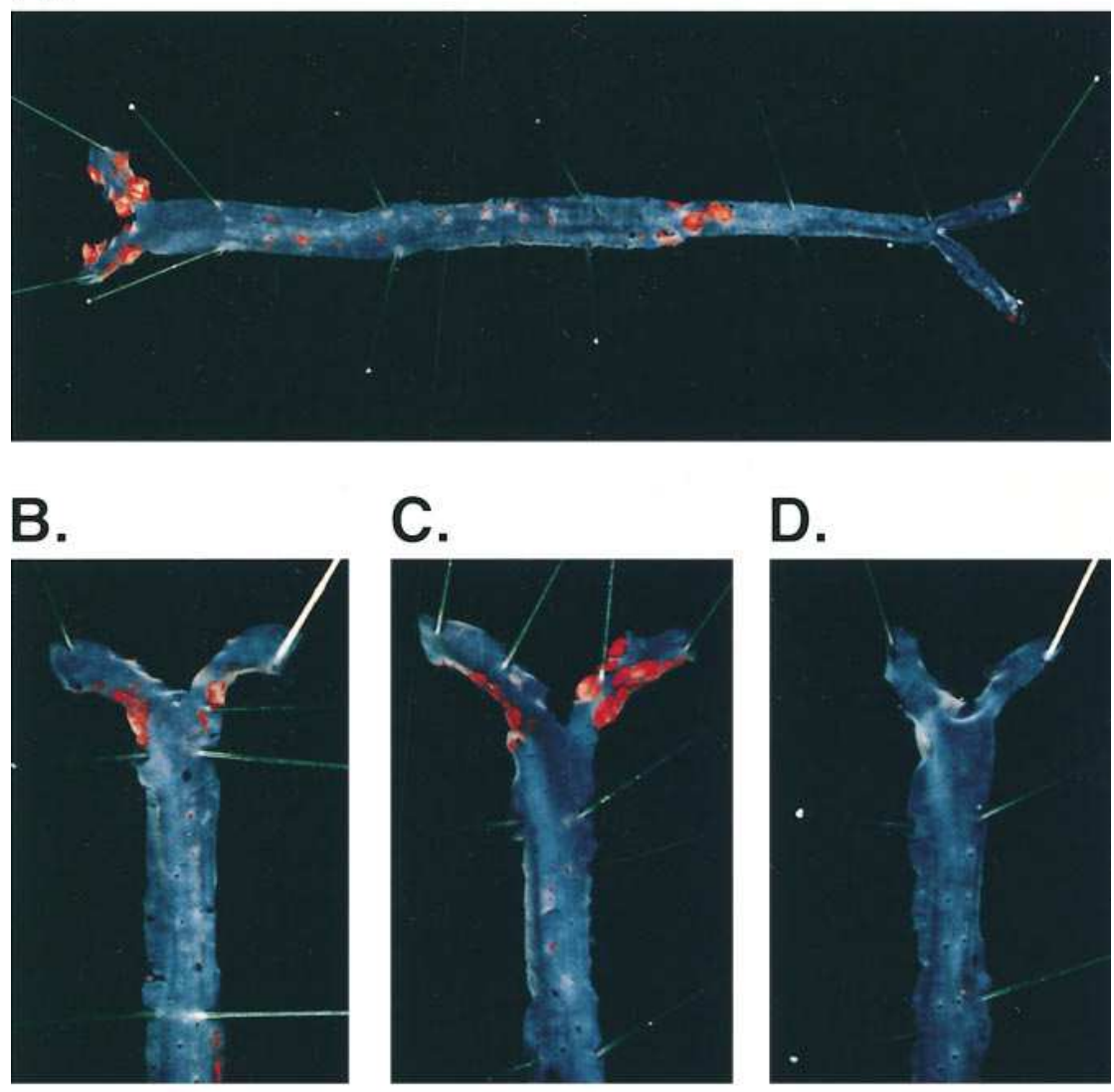

\section{E.}

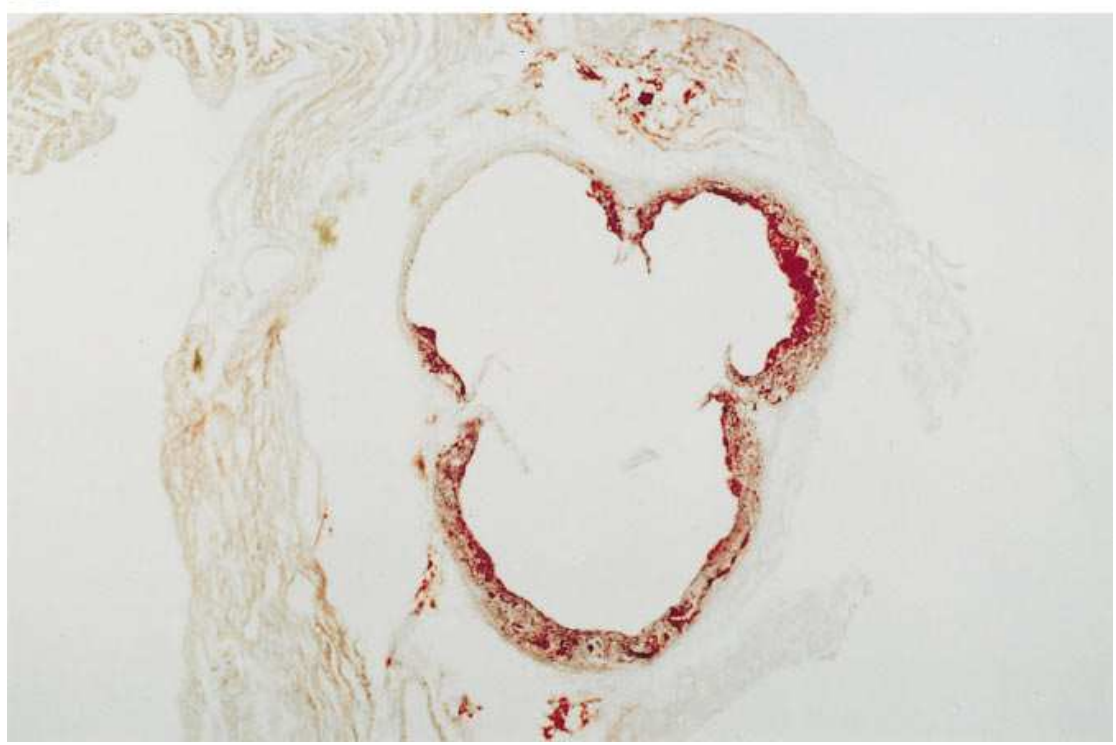

Figure 5. (A) Sudan IV-stained aorta from a apo- $B^{48 / 48}$ apo- $E^{-/-}$mouse fed a chow diet for $200 \mathrm{~d}$. Lesions were located in the aortic arch and scattered throughout the rest of the aorta, particularly at branch points, such as the origins of the mesenteric and renal arteries. $(B-D)$ Sudan IV-stained aortic arches from an apo- $B^{+/+}$ apo- $E^{-/-}$mouse $(B)$, an apo- $B^{48 / 48}$ apo- $E^{-/-}$ mouse $(C)$, and an apo- $B^{100 / 100}$ apo- $E^{-1-}$ mouse $(D)$. The apo- $B^{100 / 100}$ apo- $E^{-/-}$mice had fewer lesions than the apo- $B^{+/+}$apo- $E^{-/-}$and apo- $B^{48 / 48}$ apo- $E^{-1-}$ mice $(C)$. Oil Red O-stained section through the proximal aortic root of an apo- $B^{+/+}$ apo- $E^{-1-}$ mouse $(E)$. The atherosclerotic lesions stain red. The extent of lesions in this section was $144,740 \mu \mathrm{m}^{2}$. in the apo- $B^{100 / 100}$ apo- $E^{-/-}$mice, which had the lowest cholesterol levels. However, the extent of atherosclerosis and total plasma cholesterol levels in the three groups overlapped significantly. To determine if one genotype had significantly more (or less) atherosclerosis at any given cholesterol level, we plotted the plasma cholesterol level at $200 \mathrm{~d}$ versus the extent of lesions in the pinned-out aortas for all mice of the study (Fig. 6).
Within each genotype, the cholesterol levels at $200 \mathrm{~d}$ correlated positively with the extent of atherosclerosis $(r=0.515$, $P=0.008$ for the apo- $B^{+/+}$apo- $E^{-/-}$mice; $r=0.758, P=$ 0.0001 for the apo- $B^{100 / 100}$ apo- $E^{-1-}$ mice; and $r=0.37, P=$ 0.069 for the apo- $B^{48 / 48}$ apo- $E^{-1-}-$ mice). The reason for the somewhat lower correlation coefficient in the apo- $B^{48 / 48}$ apo- $E^{-1-}$ mice is not clear. However, the correlation was somewhat im- 


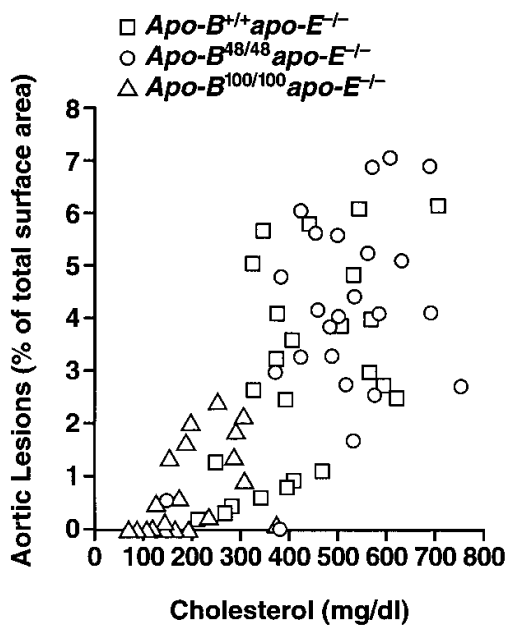

proved with the 6-mo cholesterol values $(r=0.435, P=0.029)$. When animals from all three groups were analyzed together, there was a strong positive correlation between total cholesterol levels and the amount of atherosclerosis $(r=0.715, P=$ 0.0001).

A visual inspection of Fig. 6 strongly suggested that mice of different genotypes with similar cholesterol levels had similar amounts of atherosclerosis. To put that assessment to a statistical test, we applied multivariate analysis to the analysis of the experimental variables (total cholesterol level, triglyceride level, body weight, and apo-B genotype) from all 75 mice in the study. Multivariate analysis revealed that the total cholesterol level was a very powerful predictor of extent of atherosclerosis $(P=0.0001)$. Triglyceride levels correlated negatively with lesion size $(P=0.0043)$. This correlation was mainly due to apo- $B^{+/+}$apo- $E^{-/-}$mice $(r=-0.44, P=0.0277$ for the apo- $B^{+/+}$apo- $E^{-/-}$mice; $r=-0.321, P=0.15$ for the apo- $B^{100 / 100}$ apo- $E^{-1-}$ mice; and $r=-0.19, P=0.362$ for the apo- $B^{48 / 48}$ apo- $E^{-l-}$ mice). The apo-B genotype had no independent effect on the development of atherosclerosis. These data suggest that the lipid levels in the plasma, and not the species of apo-B within the lipoproteins, are the key factors that determine susceptibility to atherosclerosis.

Interestingly, the significant relationship between the total plasma cholesterol level and the extent of lesions within each genotype was only observed with cholesterol levels obtained at $6 \mathrm{mo}$ or $200 \mathrm{~d}$. The cholesterol level measured at $7 \mathrm{wk}$ did not correlate with the extent of atherosclerosis at $200 \mathrm{~d}(r=0.119$, $P=0.572$ for the apo- $B^{+/+}$apo- $E^{-/-}$mice; $r=0.221, P=0.312$ for the apo- $B^{100 / 100}$ apo- $E^{-/-}$mice; and $r=0.195, P=0.350$ for the apo- $B^{48 / 48}$ apo- $E^{-/-}$mice). There was no significant relationship between the extent of atherosclerosis and HDL cholesterol levels in any of the three groups of animals $(r=0.068$, $P=0.747$ for the apo- $B^{+/+}$apo- $E^{-/-}$mice; $r=0.236, P=0.256$ for the apo- $B^{100 / 100}$ apo- $E^{-/-}$mice; and $r=0.087, P=0.679$ for the apo- $B^{48 / 48}$ apo- $E^{-/-}$mice).

The extent of atherosclerosis was also assessed by quantifying lesions in cross sections of the aortic root. An example of an Oil Red O-stained lesion from the aortic root of a apo- $B^{+/+}$ apo- $E^{-l-}$ mouse is shown in Fig. 5 E. Data from cross-sectional analysis of the proximal aortic root were more variable than data from the analysis of pinned-out aortas and could not be

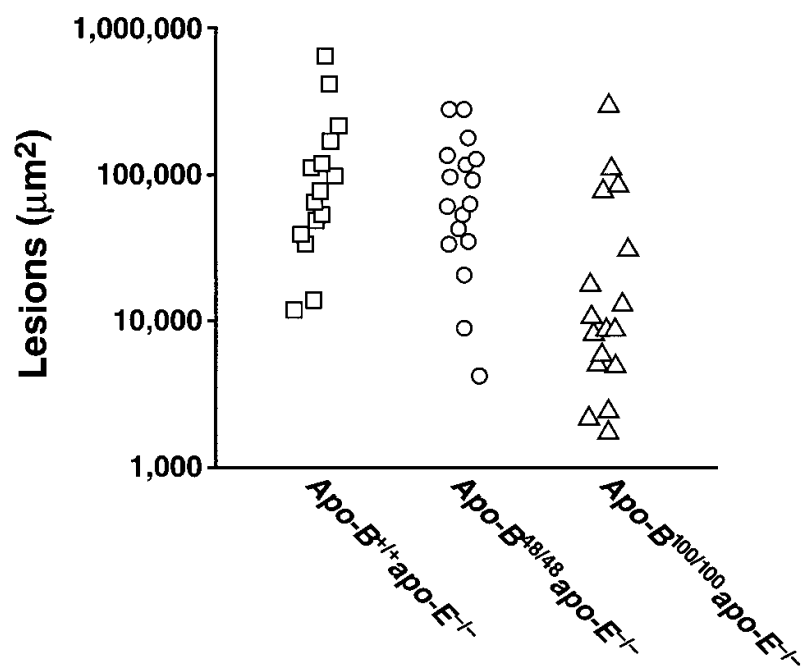

Figure 7. Extent of atherosclerotic lesions as judged by microscopic analysis of cross sections of the proximal aortic root $(n=17$ in each group).

modeled as well. In a multivariate model including cholesterol, triglycerides, and genotype as predictors, the $r^{2}$ value for extent of atherosclerosis in aortic cross sections was lower than that in the pinned-out aortas $\left(r^{2}=0.24\right.$ versus $\left.r^{2}=0.55\right)$. Also, in contrast to our findings with the pinned-out aorta data, residuals from the models showed that the cross-sectional data were highly skewed (skewness $=1.9$ ) and not normally distributed $(P<0.0001)$, thereby violating the assumptions for a valid analysis by standard statistical methods. Because of these considerations, nonparametric statistics were used to analyze the cross-sectional data. Analysis of the data with the KruskalWallis test showed no difference in the extent of atherosclerosis in aortic cross sections between the apo- $B^{+/+}$apo- $E^{-/-}$and apo- $B^{48 / 48}$ apo- $E^{-1-}$ mice (Fig. 7). However, the lesions in the apo- $B^{100 / 100}$ apo- $E^{-/-}$mice were smaller than those in the other two groups $\left(P=0.0008\right.$ versus apo- $B^{+/+}$apo- $E^{-1-}$ mice and $P=0.0049$ versus apo- $B^{48 / 48}$ apo- $E^{-/-}$mice) (Fig. 7).

Despite the nonnormal distribution of the aortic cross-sectional data, the plasma cholesterol levels correlated positively with the extent of aortic root atherosclerosis $(r=0.433, P=$ 0.0017 ) when mice from all three genotypes were analyzed as one group. A positive association between cholesterol levels and lesions was also noted within two of the groups $(r=0.477$, $P=0.052$ for the apo- $B^{+/+}$apo- $E^{-/-}$mice; $r=0.518, P=0.039$ for the apo- $B^{100 / 100}$ apo- $E^{-/-}$mice; and $r=0.145, P=0.579$ for the apo- $B^{48 / 48}$ apo- $E^{-1-}$ mice). When all three groups were analyzed together, the extent of atherosclerosis overlapped, in a manner very similar to that shown for the pinned-out aorta data in Fig. 6. In animals with similar plasma cholesterol levels, the amount of atherosclerosis measured in the aortic cross sections was similar.

Atherosclerosis was assessed in aortic cross sections and in pinned-out aortas in 17 animals of each genotype, providing us with an opportunity to assess the correlation between data obtained with the two methods. There was a statistically significant correlation between data obtained with the two methods $(r=0.592, P=0.0003$ ) (Fig. 8). However, several mice, primarily from the apo- $B^{48 / 48}$ apo- $E^{-/-}$group, had very severe ath- 


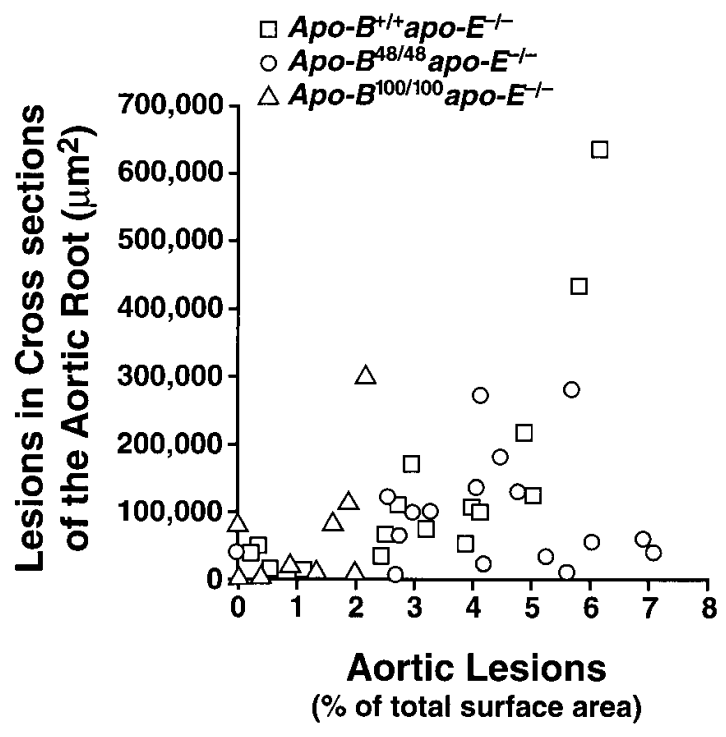

Figure 8. Correlation between the extent of atherosclerotic lesions in the pinned-out aortas and in cross sections of the proximal aortic root $(n=17$ in each group). $r=0.592(P=0.0003)$.

erosclerosis in the pinned-out aortas but only modest amounts of atherosclerosis in cross sections of the aortic root.

Our atherosclerosis studies suggested that the three groups of animals developed similar amounts of atherosclerosis in cases where the cholesterol levels were similar. Independent of cholesterol levels, we could not detect an effect of apo-B48 or apo-B100 synthesis on susceptibility to atherosclerosis, either with the pinned-out aorta data or with the aortic cross-sectional data. In interpreting this finding, it is important to note that the form of apo-B species that is synthesized has a significant effect on lipoprotein sizes and chemical compositions. The VLDL from apo- $B^{100 / 100}$ apo- $E^{-/-}$mice were more enriched in triglycerides than the VLDL from apo- $B^{48 / 48}$ apo- $E^{-1-}$ (VLDL triglycerides per protein ratios of 1.55 and 0.91 , respectively). Moreover, lipoproteins sizes differed in the three groups of animals. The mean size of the VLDL in apo- $B^{100 / 100}$ apo- $E^{-/-}$mice was significantly larger than that of the VLDL from apo- $B^{+/+}$apo- $E^{-/-}$or apo- $B^{48 / 48}$ apo- $E^{-/-}$mice, as judged by the dynamic light scattering technique (Table II). The IDL and LDL particles were also larger in the apo- ${ }^{100 / 100} a p o-E^{-/-}$ mice, although this difference was not as striking as the differ-

Table II. VLDL Particle Sizes in Six Different Groups of Mice

\begin{tabular}{lc}
\hline \multicolumn{1}{c}{ Genotype } & VLDL $(\mathrm{nm})$ \\
\hline apo- $B^{+/+}$apo $-E^{+/+}$ & $55.5 \pm 6.8$ \\
apo $-B^{48 / 48}$ apo- $E^{+/+}$ & $54.2 \pm 2.7$ \\
apo- $B^{100 / 100}$ apo- $E^{+/+}$ & $57.5 \pm 1.4$ \\
apo $-B^{+/+}$apo $-E^{-/-}$ & $43.5 \pm 2.4$ \\
apo- $B^{48 / 48}$ apo- $E^{-/-}$ & $42.7 \pm 3.0$ \\
apo- $B^{100 / 100}$ apo- $E^{-/-}$ & $60.4 \pm 2.9^{*}$
\end{tabular}

Values are means \pm SEM for three independent experiments on pooled plasma samples. ${ }^{*} P<0.001$ versus apo- $B^{+/+}$apo- $E^{-/-}$and apo- $B^{48 / 48}$ apo- $E^{-1-}$ mice. ence in VLDL particle sizes. These differences were confirmed by negative-staining electron microscopy. The mean size of particles in the VLDL-IDL fraction was $32.2 \pm 12.7 \mathrm{~nm}$ in the apo- $B^{100 / 100}$ apo- $E^{-/-}$mice versus $28.5 \pm 8.6 \mathrm{~nm}$ in the apo- $B^{48 / 48}$ apo- $E^{-/-}$mice $(P<0.001)$. In the latter experiments, $30 \%$ of the VLDL-IDL particles from the apo- $B^{100 / 100}$ apo- $E^{-/-}$mice were $>40 \mathrm{~nm}$ versus only $10 \%$ of VLDL-IDL from the apo$B^{48 / 48}$ apo- $E^{-/-}$mice. As judged by electron microscopy, the mean LDL particle size was $23.9 \pm 9.1 \mathrm{~nm}$ in the apo- $B^{100 / 100}$ apo- $E^{-/-}$mice versus $22.9 \pm 8.2 \mathrm{~nm}$ for the LDL from apo- $B^{48 / 48}$ apo- $E^{-/-}$mice $(P=0.010)$.

\section{Discussion}

High plasma levels of apo-B-containing lipoproteins unquestionably play a causal role in the development of atherosclerosis (27). However, the structural features of apo-B that contribute to its atherogenic properties are not completely understood. As a first step toward approaching this issue, we asked whether there might be intrinsic differences in the atherogenicity of lipoproteins containing the two naturally occurring forms of apo-B, apo-B100, and apo-48. To address this question experimentally, we used gene targeting to generate apo-B48-only and apo-B100-only mice (18) and then compared their susceptibility to atherosclerosis in the setting of apo-E deficiency. We chose a background of apo-E deficiency because it has been shown that apo-E-deficient mice develop advanced atherosclerotic lesions while consuming a chow diet $(14,15)$.

Plasma lipid levels were measured repeatedly during the course of our study, and the extent of atherosclerosis was assessed by two techniques: measuring lesion sizes in cross sections of the aortic root $(28,29)$ and measuring lesions in aortas that had been pinned out en face (26). Compared with the apo$B^{+/+}$apo- $E^{-/-}$mice, the apo- $B^{48 / 48}$ apo- $E^{-/-}$mice had slightly but significantly higher plasma cholesterol levels and the apo$B^{100 / 100}$ apo- $E^{-/-}$mice had lower levels. In each genotype and across all three groups of animals, the extent of atherosclerosis correlated with the plasma cholesterol levels. As judged by the analysis of pinned-out aortas, the apo- $B^{48 / 48}$ apo- $E^{-/-}$mice had more atherosclerosis than the apo- $B^{+/+}$apo- $E^{-/-}$mice, which had more than the apo- $B^{100 / 100}$ apo- $E^{-l-}$ mice. However, there was a significant amount of overlap among the three groups of animals, and mice from all three groups had similar amounts of atherosclerosis when cholesterol levels were similar. In other words, there were no data to suggest that the presence of apo$\mathrm{B} 100$ in the plasma might yield significantly more (or less) atherosclerosis than apo-B48, in cases where cholesterol levels were similar.

This conclusion-that there were probably no major differences in the intrinsic atherogenicity of apo-B48 and apo$\mathrm{B} 100$ - is subject to several caveats. One is that the apo- $B^{48 / 48}$ apo- $E^{-/-}$and apo- $B^{100 / 100}$ apo- $E^{-/-}$mice had different cholesterol levels, making it necessary for us to base our conclusions on the facts that animals with similar cholesterol levels had similar amounts of atherosclerosis, that the cholesterol versus atherosclerosis relationship appeared to be very similar in the three groups of animals, and that multivariate analysis revealed no significant effect of apo-B genotype on the development of lesions. Second, the length of the apo-B molecule has secondary effects on lipoprotein size and composition, making it difficult to draw unequivocal conclusions regarding the in- 
trinsic atherogenicity of the apo-B molecules themselves. For example, the VLDL from apo- $B^{100 / 100} a p o-E^{-/-}$mice were substantially larger and more enriched in triglycerides than the VLDL from apo- $B^{48 / 48}$ apo- $E^{-1-}$ mice. While the presence of apo-B100 in the plasma did not appear to lead to an overall increase in atherosclerosis (compared with apo-B48), it is important to realize that the presence of apo-B100 might have multiple effects on atherogenesis. For example, the larger size of the apo- $B^{100 / 100}$ apo- $E^{-/-}$VLDL might mitigate atherosclerosis, while apo-B100's additional heparin-binding domains might act to promote atherosclerosis. A third caveat is that the HDL cholesterol levels differed slightly in the three groups of mice, with the apo- $B^{100 / 100}$ apo- $E^{-/-}$mice having significantly higher HDL levels.

The lower IDL and LDL cholesterol levels in the apo- $B^{100 / 100}$ apo- $E^{-/-}$mice (18) were almost certainly due to the fact that apo-B100-containing IDL and LDL can be removed from the plasma by the LDL receptor. The VLDL cholesterol levels in the apo- $B^{100 / 100}$ apo- $E^{-l-}$ mice do not appear to be reduced, as judged by FPLC fractionation studies (18), probably because the apo-B100 molecules on large VLDL particles are not in the proper conformation for binding to the LDL receptor (30). To analyze this issue further, we have begun to compare the turnover of apo-B48- and apo-B100-containing lipoproteins in apo- $B^{+/+}$apo- $E^{-/-}$mice (Véniant, M., and S. Young, unpublished data). Preliminary results indicate that apo-B100-containing LDL are cleared significantly more rapidly than the apo-B48-containing LDL, while the clearance rates for apoB100-containing VLDL are no greater than those for apoB48-containing VLDL.

To compare the intrinsic atherogenicities of the apo-B48 and apo-B100 molecules themselves, it would be desirable to compare them directly under conditions in which every experimental variable (such as plasma cholesterol concentration, lipoprotein size, and diet) was identical in every group of animals. Unfortunately, we doubt that it will be possible to attain such ideal experimental conditions. For example, one could probably match cholesterol levels in apo- $B^{48 / 48}$ apo- $E^{-/-}$and apo- $B^{100 / 100}$ apo- $E^{-/-}$mice with different diets, but it is questionable whether one could match both cholesterol levels and triglyceride levels. Differential effects of different diets on lipoprotein composition and gene expression in the liver and arterial wall could also confound the interpretation of the results. Additionally, one could analyze atherosclerosis in apo-B48only and apo-B100-only mice in the setting of either LDL receptor deficiency (31) or combined apo-E/LDL receptor deficiency (32). However, we strongly suspect that the cholesterol levels in these animals probably would not be well-matched. As we continue to test the proposition that apo-B48 and apoB100 have similar intrinsic capacities to promote atherogenesis, we will probably have to accept the fact that it will be next to impossible to compare the atherogenicity of apo-B48 and apo-B100 in settings in which every experimental variable is well-matched.

In this study, we used two different independent methods to measure atherosclerosis: standard microscopic analysis of cross sections of the aortic root $(28,29)$, and the more recent en face analysis of the pinned-out aorta reported by Tangirala et al. (26). In animals with advanced lesions, such as the apoE-deficient animals studied here, quantifying atherosclerosis in the pinned-out aortas carries significant advantages. First, the data are less variable than those obtained with the aortic cross-sectional analysis. The pinned-out aorta data showed little skewness $(-0.1)$ whereas the aortic cross section data were highly skewed (1.9). From the standpoint of planning an experiment, a lower level of experimental variability translates into a need for fewer animals to achieve a study with identical power. $^{2}$ Moreover, the analysis of pinned-out aortas is less time- and labor-intensive than analysis of aortic cross sections.

Several findings regarding the plasma lipids were interesting and noteworthy. First, plasma cholesterol levels correlated strongly with the extent of lesions in each genotype. To our knowledge, no one has yet reported a positive correlation between cholesterol levels and lesions in apo-E-deficient mice, even in mice more extensively backcrossed into the C57BL/6 strain. Second, cholesterol levels at $7 \mathrm{wk}$ of age did not correlate with extent of atherosclerosis at $200 \mathrm{~d}$. Thus, single cholesterol measurements at this stage of maturity apparently cannot be used to predict the extent of atherosclerosis later in life. Third, the apo-B100-only mice had higher triglyceride levels throughout the study. Higher triglyceride levels in apo-B100only mice are also observed in the setting of apo-E expression (18). Although we do not know the mechanism for the higher triglyceride levels, we have speculated previously (18) that the apo-B100 molecule may not permit as complete hydrolysis of triglycerides in lipoproteins.

An unexpected finding was that there were significant weight differences between the different groups of animals, with the apo- $B^{48 / 48}$ apo- $E^{-/-}$mice being significantly heavier and the apo- $B^{100 / 100}$ apo- $E^{-/-}$mice being lighter than apo- $B^{+/+}$ apo- $E^{-/-}$mice. We do not know whether this relates to differences in adiposity or to lean body mass, and it is probably prudent to be cautious about these observations because they were not made in inbred strains. However, the fact that the apo-B48-only and apo-B100-only mutations produced opposite effects on body weight suggests that the intrinsic differences between the two molecules may affect fuel metabolism and nutritional status. In support of this interpretation, Lyn Powell-Braxton has recently measured body weights in 24 hybrid APOBEC-1 knockout mice (33) (which synthesize only apo-B100) and 18 wild-type littermate controls and documented that the APOBEC-1 knockout mice had significantly lower body weights $(P=0.0043)$ (Powell-Braxton, L., personal communication).

We suspect that the apo-E-deficient mouse models characterized in this study may prove to be useful for future studies of lipoprotein metabolism and atherosclerosis (the animals used in this study are available from the investigators and will be placed in the Jackson Laboratories). For studies of lipoprotein metabolism, the intrinsic metabolic heterogeneity resulting from the synthesis of both apo-B48 and apo-B100 may be

\footnotetext{
2. For example, using the data from this study, we calculated that, to attain an $80 \%$ chance of detecting a $25 \%$ difference in atherosclerosis between apo- $B^{48 / 48}$ apo- $E^{-1-}$ and apo- $B^{+/+}$apo- $E^{-/-}$mice at the $P=$ 0.05 level, 48 mice would be required for the pinned-out aorta analysis versus 240 mice for the cross-sectional analysis. Similarly, to attain an $80 \%$ chance of detecting a $15 \%$ difference between apo- $B^{100 / 100}$ apo- $E^{-1-}$ and apo- $B^{+/+}$apo- $E^{-/-}$mice at the $P=0.05$ level would require 12 animals for the pinned-out aorta analysis and 63 for the cross-sectional analysis, respectively. (Even though the cross-sectional data are not normally distributed, it is appropriate to estimate the sample size using this type of power calculation [34]).
} 
undesirable, making the use of apo- $B^{48 / 48}$ apo- $E^{-/-}$or apo- $B^{100 / 100}$ apo- $E^{-1-}$ mice attractive. For some atherosclerosis studies, it might be useful to use apo- $B^{48 / 48}$ apo- $E^{-/-}$mice because they develop more extensive lesions than the apo- $B^{+/+}$apo- $E^{-/-}$ mice. On the other hand, some investigators might want to use apo- $B^{100 / 100}$ apo- $E^{-/-}$mice, which develop atherosclerotic lesions without severe hypercholesterolemia.

\section{Acknowledgments}

We thank W. Palinski for showing us the pinned-out aorta technique; J. Carroll, M. McCarthy, and A. Corder for graphics; and S. Ordway and G. Howard for reviewing the manuscript.

This work was supported by NIH grant HL47660.

\section{References}

1. Havel, R.J., and J.P. Kane. 1995. Introduction: structure and metabolism of plasma lipoproteins. In The Metabolic and Molecular Bases of Inherited Disease. 7th ed., Vol. 2. C.R. Scriver, A.L. Beaudet, W.S. Sly, and D. Valle, editors. McGraw-Hill Inc., New York. 1841-1851.

2. Young, S.G. 1990. Recent progress in understanding apolipoprotein B. Circulation. 82:1574-1594.

3. Nielsen, L.B., S. Stender, M. Jauhiainen, and B.G. Nordestgaard. 1996. Preferential influx and decreased fractional loss of lipoprotein(a) in atherosclerotic compared with nonlesioned rabbit aorta. J. Clin. Invest. 98:563-571.

4. Steinberg, D., S. Parthasarathy, T.E. Carew, T.C. Khoo, and J.L. Witztum. 1989. Beyond cholesterol. Modifications of low-density lipoprotein that increase its atherogenicity. N. Engl. J. Med. 320:915-924.

5. Henriksen, T., E.M. Mahoney, and D. Steinberg. 1981. Enhanced macrophage degradation of low density lipoprotein previously incubated with cultured endothelial cells: recognition by receptors for acetylated low density lipoproteins. Proc. Natl. Acad. Sci. USA. 78:6499-6503.

6. Quinn, M.T., S. Parthasarathy, and D. Steinberg. 1985. Endothelial cellderived chemotactic activity for mouse peritoneal macrophages and the effects of modified forms of low density lipoprotein. Proc. Natl. Acad. Sci. USA. 82: 5949-5953.

7. Cushing, S.D., J.A. Berliner, A.J. Valente, M.C. Territo, M. Navab, F. Parhami, R. Gerrity, C.J. Schwartz, and A.M. Fogelman. 1990. Minimally modified low density lipoprotein induces monocyte chemotactic protein 1 in human endothelial cells and smooth muscle cells. Proc. Natl. Acad. Sci. USA. 87:51345138 .

8. Weisgraber, K.H., and S.C. Rall, Jr. 1987. Human apolipoprotein B-100 heparin-binding sites. J. Biol. Chem. 262:11097-11103.

9. Zilversmit, D.B. 1979. Atherogenesis: a postprandial phenomenon. Circulation. 60:473-485.

10. Mahley, R.W. 1981. The role of dietary fat and cholesterol in atherosclerosis and lipoprotein metabolism. West. J. Med. 134:34-42.

11. Bergeron, N., and R.J. Havel. 1996. Prolonged postprandial responses of lipids and apolipoproteins in triglyceride-rich lipoproteins of individuals expressing an apolipoprotein $\epsilon 4$ allele. J. Clin. Invest. 97:65-72.

12. Purcell-Huynh, D.A., R.V. Farese, Jr., D.F. Johnson, L.M. Flynn, V. Pierotti, D.L. Newland, M.F. Linton, D.A. Sanan, and S.G. Young. 1995. Transgenic mice expressing high levels of human apolipoprotein B develop severe atherosclerotic lesions in response to a high-fat diet. J. Clin. Invest. 95:22462257.

13. Callow, M.J., J. Verstuyft, R. Tangirala, W. Palinski, and E.M. Rubin. 1995. Atherogenesis in transgenic mice with human apolipoprotein B and lipoprotein (a). J. Clin. Invest. 96:1639-1646.

14. Nakashima, Y., A.S. Plump, E.W. Raines, J.L. Breslow, and R. Ross. 1994. ApoE-deficient mice develop lesions of all phases of atherosclerosis throughout the arterial tree. Arterioscler. Thromb. 14:133-140.

15. Reddick, R.L., S.H. Zhang, and N. Maeda. 1994. Atherosclerosis in mice lacking apo E. Evaluation of lesional development and progression. Arterioscler. Thromb. 14:141-147.
16. Ishibashi, S., J.L. Goldstein, M.S. Brown, J. Herz, and D.K. Burns. 1994. Massive xanthomatosis and atherosclerosis in cholesterol-fed low density lipoprotein receptor-negative mice. J. Clin. Invest. 93:1885-1893.

17. Purcell-Huynh, D.A., A. Weinreb, L.W. Castellani, M. Mehrabian, M.H. Doolittle, and A.J. Lusis. 1995. Genetic factors in lipoprotein metabolism. Analysis of a genetic cross between inbred mouse strains NZB/BINJ and SM/J using a complete linkage map approach. J. Clin. Invest. 96:1845-1858.

18. Farese, R.V., Jr., M.M. Véniant, C.M. Cham, L.M. Flynn, V. Pierotti, J.F. Loring, M. Traber, S. Ruland, R.S. Stokowski, D. Huszar, and S.G. Young. 1996. Phenotypic analysis of mice expressing exclusively apolipoprotein B48 or apolipoprotein B100. Proc. Natl. Acad. Sci. USA. 93:6393-6398.

19. Piedrahita, J.A., S.H. Zhang, J.R. Hagaman, P.M. Oliver, and N. Maeda. 1992. Generation of mice carrying a mutant apolipoprotein E gene inactivated by gene targeting in embryonic stem cells. Proc. Natl. Acad. Sci. USA. 89:4471-4475.

20. McCormick, S.P.A., J.K. Ng, M. Véniant, J. Borén, V. Pierotti, L.M. Flynn, D.S. Grass, A. Connolly, and S.G. Young. 1996. Transgenic mice that overexpress mouse apolipoprotein B. Evidence that the DNA sequences controlling intestinal expression of the apolipoprotein B gene are distant from the structural gene. J. Biol. Chem. 271:11963-11970.

21. Farese, R.V., Jr., S.L. Ruland, L.M. Flynn, R.P. Stokowski, and S.G. Young. 1995. Knockout of the mouse apolipoprotein B gene results in embryonic lethality in homozygotes and protection against diet-induced hypercholesterolemia in heterozygotes. Proc. Natl. Acad. Sci. USA. 92:1774-1778.

22. Walzem, R.L., P.A. Davis, and R.J. Hansen. 1994. Overfeeding increases very low density lipoprotein diameter and causes the appearance of a unique lipoprotein particle in association with failed yolk deposition. J. Lipid Res. 35:1354-1366.

23. Hamilton, R.L. 1969. Ultrastructural aspects of hepatic lipoprotein synthesis and secretion. In Proceedings of the 1968 Deuel Conference on Lipids on the Turnover of Lipids and Lipoproteins. G. Cowgill, D.L. Estrich, and P.D. Wood, editors. U.S. Department of Health, Education, and Welfare, Bethesda, MD. 3-31.

24. Forte, T., and A.V. Nichols. 1972. Application of electron microscopy to the study of plasma lipoprotein structure. Adv. Lipid Res. 10:1-41.

25. Castle, C.K., J.R. Colca, and G.W. Melchior. 1993. Lipoprotein profile characterization of the KKA $\mathrm{K}^{\mathrm{y}}$ mouse, a rodent model of type II diabetes, before and after treatment with the insulin-sensitizing agent pioglitazone. Arterioscler. Thromb. 13:302-309.

26. Tangirala, R.K., E.M. Rubin, and W. Palinski. 1995. Quantitation of atherosclerosis in murine models: correlation between lesions in the aortic origin and in the entire aorta, and differences in the extent of lesions between sexes in LDL receptor-deficient and apolipoprotein E-deficient mice. J. Lipid Res. 36:2320-2328.

27. The Expert Panel. 1988. Report of the National Cholesterol Education Program Expert Panel on Detection, Evaluation, and Treatment of High Blood Cholesterol in Adults. Arch. Intern. Med. 148:36-69.

28. Paigen, B., A. Morrow, C. Brandon, D. Mitchell, and P. Holmes. 1985. Variation in susceptibility to atherosclerosis among inbred strains of mice. Atherosclerosis. 57:65-73.

29. Paigen, B., B.Y. Ishida, J. Verstuyft, R.B. Winters, and D. Albee. 1990. Atherosclerosis susceptibility differences among progenitors of recombinant inbred strains of mice. Arteriosclerosis. 10:316-323.

30. Krul, E.S., M.J. Tikkanen, T.G. Cole, J.M. Davie, and G. Schonfeld. 1985. Roles of apolipoproteins B and E in the cellular binding of very low density lipoproteins. J. Clin. Invest. 75:361-369.

31. Ishibashi, S., M.S. Brown, J.L. Goldstein, R.D. Gerard, R.E. Hammer, and J. Herz. 1993. Hypercholesterolemia in low density lipoprotein receptor knockout mice and its reversal by adenovirus-mediated gene delivery. J. Clin. Invest. 92:883-893.

32. Ishibashi, S., J. Herz, N. Maeda, J.L. Goldstein, and M.S. Brown. 1994 The two-receptor model of lipoprotein clearance: tests of the hypothesis in "knockout" mice lacking the low density lipoprotein receptor, apolipoprotein E, or both proteins. Proc. Natl. Acad. Sci. USA. 91:4431-4435.

33. Hirano, K.-I., S.G. Young, R.V. Farese, Jr., J. Ng, E. Sande, C. Warburton, L.M. Powell-Braxton, and N.O. Davidson. 1996. Targeted disruption of the mouse apobec-1 gene abolishes apolipoprotein B mRNA editing and eliminates apolipoprotein B48. J. Biol. Chem. 271:9887-9890.

34. Hollis, N.E. 1990. A statistical approach for calculating the minimum number of animals needed in research. ILAR News. 32:11-16. 